\title{
ENERGIA EÓLICA E A CRIAÇÃO DE CONFLITOS: OCUPAÇÃO DOS ESPAÇOS DE LAZER EM UMA COMUNIDADE NO NORDESTE DO BRASIL
}

\author{
Leilane Oliveira Chaves ${ }^{1}$ \\ Christian Brannstrom ${ }^{2}$ \\ Edson Vicente da Silva ${ }^{3}$
}

\section{Resumo}

A região nordeste do Brasil, especialmente nas áreas costeiras, tem-se assistido a um rápido crescimento no número de parques eólicos, bem como conflitos econômicos e socioambientais envolvendo residentes de comunidades tradicionais, que muitas vezes são "invisíveis" para as elites políticas e econômicas. O presente artigo analisa como a instalação de um parque eólico nos campos de dunas na comunidade do Cumbe, município de Aracati, estado do Ceará tem interferido nas formas de convivência da comunidade com o seu território. Dessa forma o estudo colabora na ampliação de uma bibliografia nacional e internacional, tendo em vista a possibilidade de inclusão dos espaços de lazer nas discussões sobre os impactos dos projetos eólicos, além de contribuir para melhorar a visibilidade dos conflitos em territórios tradicionais brasileiros.

Palavras-chave: Energia eólica, espaços de lazer, conflito.

\section{WIND POWER AND THE CREATION OF CONFLICTS: OCCUPATION OF LEISURE SPACES IN A COMMUNITY IN NORTHEAST OF BRAZIL}

\begin{abstract}
Northeastern Brazil, particularly coastal areas, have witnessed rapid increase in the number of wind farms and economic, social, and environmental conflicts with nearby residents of traditional communities, which are often made to be "invisible" through the actions of political and economic elites. This paper analyzes how the construction of a wind farm on a dune field in the Cumbe community, Aracati municipality, Ceará state, has affected the ways in which residents interact with their territory. Our study contributes to national and international scholarship by adding leisure spaces into discussions regarding impacts of wind farms and contributes to making conflicts between wind farms and traditional communities in Brazil more visible.
\end{abstract}

Key words: wind power, leisure spaces, conflict.

\footnotetext{
${ }^{1}$ Doutoranda do Programa de Pós-graduação em Desenvolvimento e Meio Ambiente (PRODEMA/UFC). E-mail: leilane_chaves@hotmail.com.

${ }^{2}$ Professor doutor da Texas A\&M University. E-mail: cbrannst@tamu.edu.

${ }^{3}$ Professor titular da Universidade Federal do Ceará (1997) e docente dos programas de pós- graduação em Geografia (PPGG/UFC) e em Desenvolvimento e Meio Ambiente (PRODEMA/UFC) da Universidade Federal do Ceará E-mail: cacauceara@gmail.com.
}

Sociedade e Território - Natal. Vol. 29, N. 2, p. 49-69, Jul./Dez. de 2017 


\section{ENERGÍA EÓLICA Y LA CREACIÓN DE CONFLICTOS: OCUPACIÓN DE LOS ESPACIOS DE ESPARCIMIENTO EN UNA COMUNIDAD DEL NORESTE DE BRASIL}

\section{Resumen}

La región noreste de Brasil, especialmente en las áreas costeras, ha presenciado un crecimiento rápido en el número de parques eólicos, así como conflictos económicos y socio ambientales involucrando a los residentes de comunidades tradicionales, que muchas veces son invisibles para las élites políticas y económicas. Este trabajo analiza como la instalación de un parque eólico sobre los campos de dunas cercanos a la comunidad de Cumbe, Municipio Aracati, estado de Ceará ha interferido en las formas de convivencia de la comunidad con su territorio. De esta forma el estudio colabora en la ampliación de una bibliografía nacional e internacional, considerando la posibilidad de inclusión de los espacios de esparcimiento en las discusiones sobre los impactos de los proyectos eólicos, además de contribuir en dar visibilidad a los conflictos en territorios tradicionales brasileños.

Palabras clave: Energía eólica, espacios de esparcimiento, conflicto.

\section{INTRODUÇÃO}

As energias renováveis têm uma relevância global devido aos debates sobre a melhoria dos padrões de vida da população, as preocupações sobre as mudanças climáticas, e o crescimento da demanda energética mundial (MARTINS; GUARNIERI; PEREIRA, 2008; PACALA; SOCOLOW, 2004). Segundo a Agência Internacional da Energia (IEA), no ano 2015 houveram novas instalações de energia eólica (63 GW) e solar (49 GW), o que representa mais da metade de toda a nova capacidade de energia elétrica.

No Brasil, a implementação da energia eólica apresentou um amplo crescimento depois de 2001, quando a crise energética, devido ao baixo nível de reservatórios das hidrelétricas, motivou o governo federal a criar políticas urgentes para diversificar a matriz energética brasileira. Estas políticas incluem a criação do Programa Nacional de Incentivos às Fontes Alternativas de Energia (PROINFA), a produção de informações sobre a qualidade dos ventos, a criação de leilões para atrair investimentos em parques eólicos e o fornecimento de crédito subsidiado através do Banco Nacional de Desenvolvimento Econômico e Social (AQUILA et al.; 2017; JUÁREZ et al.; 2014; SILVA et al.; 2016). O licenciamento ambiental simplificado complementou os subsídios e incentivos federais, permitindo uma maneira simples para os investidores se aliarem com as elites locais para obter terrenos para a localização dos parques eólicos (GORAYEB; BRANNSTROM, 2016). Estas políticas 
legitimaram e normatizaram os territórios costeiros, que frequentemente apresentam incertezas fundiárias (BRANNSTROM et al.; 2017), para empreendimentos energéticos renováveis que, por sua natureza, ocupam grandes extensões de terra para produzir electricidade (SCHEIDEL; SORMAN, 2012; HUBER; MCCARTHY, 2017).

A região Nordeste, em especial nas áreas litorâneas do Ceará e Rio Grande do Norte apresentam o maior potencial eólico do Brasil (BRASIL, 2001). Essas áreas em grande parte são ocupadas por populações e comunidades tradicionais que necessitam dos recursos presentes no território para sua reprodução econômica e sociocultural. Por não possuírem a regularização fundiária das terras que ocupam, muitos grupos estão vulneráveis as pressões que a instalação de grandes projetos pode proporcionar (BRANNSTROM et al.; 2017). Porém, estudos de Filgueiras e Silva (2003), Juarez et al. (2014) e Silva et al. (2005) demostram com muito otimismo análises de engenheiros que argumentam que a energia eólica é compatível com atividades rurais e que aumenta a renda da população rural. Entretanto, avanços na quantidade de parques eólicos no Ceará tem revelado a existência de muitos conflitos pela impossibilidade por parte dos residentes locais de continuarem usufruindo do território de forma plena.

Cientistas e engenheiros argumentam que a população global poderia ter toda a sua eletricidade gerada por vento, água e sol até o ano 2050, caso não haja barreiras sociais e políticas que impeçam a transição à energia renovável (JACOBSON; DELUCCHI, 2011). Nas ciências sociais, muitos pesquisadores entendem estas barreiras como o "social gap", definido como o desencontro entre dois fenômenos: existe uma boa aceitação de energia renovável no nível nacional enquanto existem vários casos de oposição e rejeição dos projetos em determinados locais (BELL et al.; 2013). Estes pesquisadores destacam que motivos multidimensionais justificam a oposição local à energia renovável.

Pasqualetti (2011a; 2011b), ao investigar correspondências entre os motivos a rejeição ou oposição quanto a energia eólica, identifica a partir de estudos de casos, em diferentes localidades, as possíveis explicações da resistência pública aos projetos eólicos. Várias características geográfica-paisagísticas, destacadas por geógrafos como Pasqualetti (2011a, 2011b), explicam a origem da oposição à energia eólica, que é especialmente forte no período da construção do empreendimento; entre elas, a identidade do território, a estabilidade da paisagem, e o vínculo entre a comunidade e o território. Pasqualetti (2011b) sugere que empreendimentos eólicos deveriam ter melhor consideração dos aspectos sociais, incorporar um bom entendimento da "paisagem humana" no local e gerar benefícios locais. Para Sociedade e Território - Natal. Vol. 29, N. 2, p. 49-69, Jul./Dez. de 2017 
Pasqualetti (2011a, p. 914), a interligação dos estudos de caso contribuiu para a elaboração de um parâmetro de resposta pública de oposição ao projeto eólico. Dentre as diversas questões apontadas, cinco foram mais consistentes: a imobilidade - a energia eólica não se concilia com os aspectos naturais, culturais e sociais existentes; a imutabilidade - as pessoas não se adaptam a mudanças bruscas na paisagem, pois a constância da paisagem concede tranquilidade as pessoas; solidariedade - as relações comunitárias são interrompidas após a chegada da energia eólica; imposição - a população não está envolvida no projeto eólico, muitas vezes não recebendo nenhum tipo de rendimento; e lugar (place) - as relações afetivas com o local são comprometidas.

As alterações nos espaços comunitários de lazer originadas após a instalação do parque eólico no Cumbe representam o foco do presente artigo. O conflito entre a comunidade e o parque eólico ganhou maior repercussão na mídia e na bibliografia após o fechamento da estrada que permite acesso ao parque eólico (BROWN, 2011). Porém, alguns conceitos da bibliografia alimentam outra interpretação, não priorizando os vínculos afetivos com o local onde o parque eólico foi implementado. A ocupação de áreas de lazer foi um elemento que aumentou o conflito entre comunidade e empresa eólica por causa das relações afetivas com as dunas, as lagoas interdunares e o mar.

Acserald (2004), ao abordar os conflitos socioambientais envolvendo os territórios tradicionais, destaca que o que constitui um determinado ambiente para um grupo social vai depender da relação que esse grupo mantém com o lugar. Os laços culturais também devem ser considerados. O autor exemplifica essa relação, estabelecendo uma discussão entre o confronto existente em algumas regiões do Brasil, envolvendo povos indígenas e grandes empresas geradoras de hidroeletricidade, onde o rio vai representar sentidos diferenciados, não possuindo a mesma lógica de valor para os diferentes agentes sociais.

Para resumir, em muitos casos, na Europa e nos Estados Unidos, o conflito e a oposição entre a comunidade e o parque eólico é mais forte durante a construção do empreendimento do que na fase de manutenção (Pasqualetti 2011b). No caso do Cumbe, o conflito prolongou-se bem depois do fechamento da estrada, em 2009, que ocorreu durante a fase de construção. Por quê? Entendemos que as relações da comunidade com as dunas, lagoas interdunares e o mar, interpretada pelas questões imutabilidade, solidariedade, imposição e lugar, criaram um conflito permanente de difícil resolução, mesmo após a existência de medidas compensatórias. Acredita-se que as políticas de mitigação não são suficientes para a disolução dos conflitos, tendo em vista que a afetividade tem contribuído Sociedade e Território - Natal. Vol. 29, N. 2, p. 49-69, Jul./Dez. de 2017 
para a manutenção dos conflitos. A presença de relações semelhantes entre comunidades e territórios, em outros locais no litoral brasileiro, podem criar outros conflitos permanentes.

\section{MATERIAIS E MÉTODOS}

A pesquisa de campo concentra-se na comunidade do Cumbe, município de Aracati, litoral leste do Ceará. A comunidade possuiu 168 famílias (702 residentes), que sobrevivem da pesca no mar e no rio, coleta de mariscos, cultivo de alimentos, produção de artesanato, criação de animais e dos pequenos comércios. Em 2010, alguns moradores da comunidade se autodefiniram como quilombolas resultando na criação da Associação Quilombola do Cumbe. Esse movimento resultou na inclusão da comunidade no Cadastro Geral das Comunidades Remanescentes de Quilombos, recebendo em 2014 da Fundação Cultural Palmares (FCP), a certidão de auto definição. Em 2017, o território encontra-se em processo de demarcação das terras requeridas junto ao Instituto de Colonização e Reforma Agrária (INCRA).

A escolha dessa comunidade para o estudo foi motivada pela instalação em 2008 de um parque de energia eólica com 67 aerogeradores com potencial de 138,5 MW em uma área em torno de 1.546 ha, ocupando parte do território da comunidade (FIGURA 1).

Figura 1: Localização geográfica do Cumbe, litoral leste do estado do Ceará

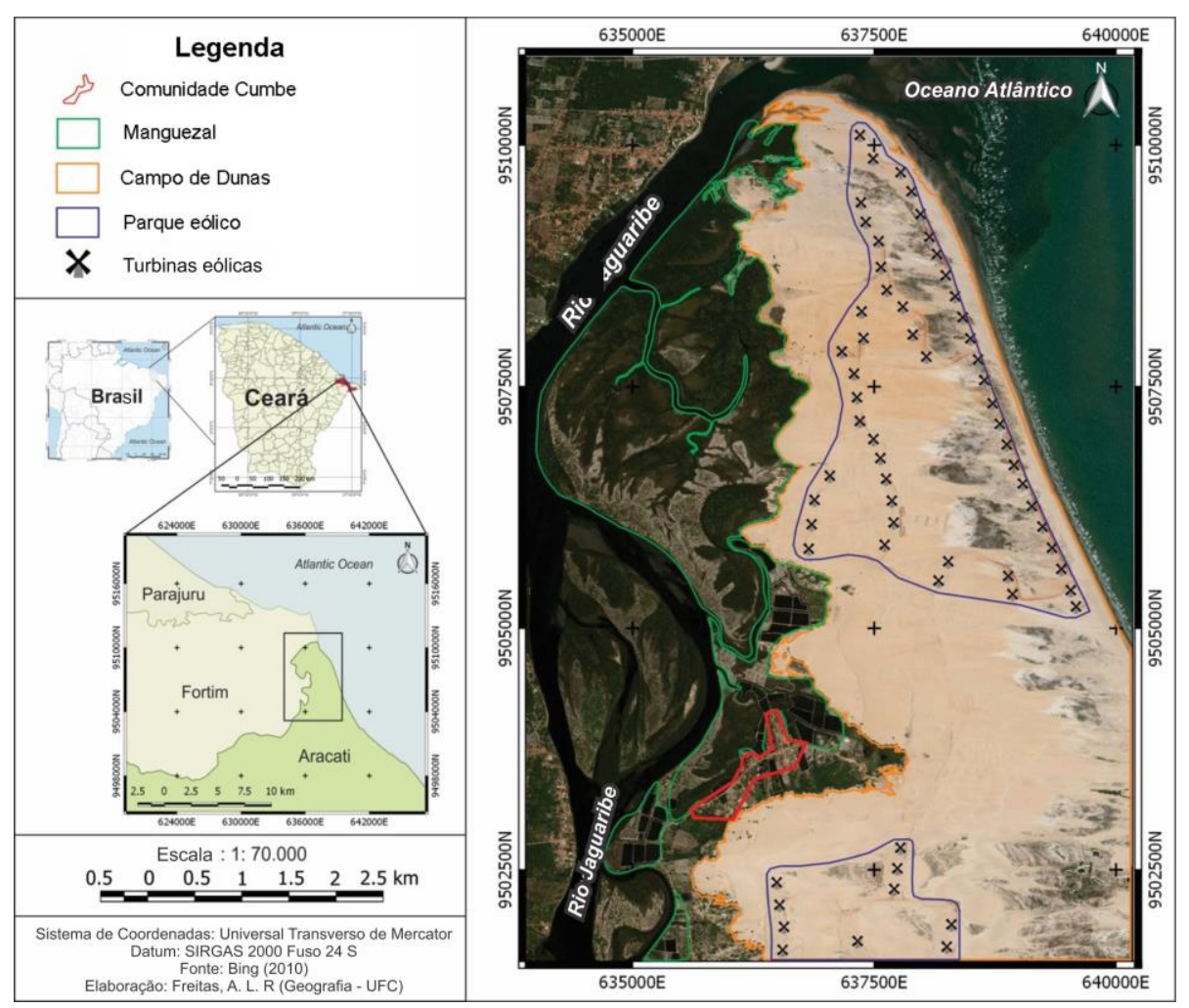

Fonte: Leilane Oliveira Chaves, 2017. 
Embora muitos dos impactos negativos presentes em 2017 no Cumbe tenham sido motivados pela implantação da maricultura em 1998, a construção de um parque eólico em 2008 tornou-se foco de numerosos conflitos, em especial por limitações de acesso ao território e seus recursos. Por isso, o Cumbe se tornou um dos lugares mais estudados nos últimos anos sobre conflitos é́licos no Brasil, provavelmente devido ao fechamento da estrada por um grupo de moradores, por 19 dias, em setembro de 2009, reivindicando do empreendedor do parque eólico medidas que atenuassem os transtornos gerados por sua instalação.

Diferentes impactos associados à implantação do parque eólico foram detectados na localidade como interferências na mobilidade pelos campos de dunas, soterramento e privatização das lagoas interdunares, ampliação dos conflitos internos, alteração da paisagem estética, modificação das atividades de subsistência e alteração nos espaços de lazer (LIMA, 2008; MEIRELES, 2011; BROWN, 2011; PINTO et al., 2014). Mesmo apresentando uma diversidade de estudos pouco se sabe sobre as interferências do projeto eólico nos espaços de lazer da comunidade. Observa-se uma lacuna na bibliografia no que se refere aos espaços de lazer, bem como as dimensões afetivas do espaço e do território no prolongamento dos conflitos tanto na fase de construção do empreendimento como na fase de manutenção do parque eólico.

Para a coleta de dados inicialmente foram realizadas duas reuniões com lideranças da Associação Quilombola do Cumbe para solicitação de autorização para o desenvolvimento da pesquisa junto à comunidade e ao Comitê de Ética de Pesquisa da Universidade Federal do Ceará (UFC). Os trabalhos de campo ocorreram no período de maio a novembro de 2016, totalizando 9 visitas a comunidade, que intercalaram momentos de observação, atividades de workshops e aplicação de questionários. A metodologia interligou diferentes instrumentos para a coleta de dados como a observação participante, diário de campo e aplicação aleatória de questionários com residentes locais. O estudo não contemplou a coleta de dados da empresa do parque eólico devido ao conflito entre a empresa e a comunidade. A natureza do conflito criou um clima desfavorável à obtenção de dados de todas as partes do conflito.

A observação em campo permitiu vivenciar a realidade da comunidade, possibilitando a manutenção dos vínculos com os moradores locais, sendo um recurso para a inserção e integração dos pesquisadores nas práticas e representações vivenciadas pelos grupos estudados (DENCKER, 1998; SERVA; JAIME, 1995; PROENÇA, 2007). Enquanto técnica de investigação propiciou o estabelecimento de relações mais próximas com os sujeitos da 
pesquisa, vivenciando questões cotidianas e assegurando uma leitura real das simbologias e vocábulos do grupo.

No decorrer das vivências também ocorreram participações nas reuniões da associação e em momentos festivos. As atividades de workshops ocorreram em todas as visitas realizadas a comunidade como uma forma de integrar as pessoas, conhecer melhor os moradores e até mesmo como uma forma de amenizar os conflitos internos, já que o processo de titularização das terras ocasionou uma forte tensão política na comunidade. Os workshops envolveram práticas de resgate cultural e valorização da culinária local, higiene, armazenamento e aproveitamento integral dos alimentos e confecção de adornos pessoais. Essas atividades possibilitaram uma maior aceitação na comunidade.

Estabelecido o contato inicial com os moradores, deu-se início a preparação dos questionários. A escolha das famílias ocorreu de forma aleatória, totalizando 19 residências. A aplicação do questionário teve como finalidade gerar informações sobre as principais formas de sustento familiar (recursos, renda e atividades) e os impactos gerados pelo parque eólico, inclusive nos espaços de lazer. A construção do questionário se apoiou na base conceitual de meios de vida (BEBBINGTON, 1999), orientado por pesquisas efetuadas no litoral baiano (SANTOS; BRANNSTROM, 2015) e utilizando perguntas específicas sobre conflitos com o parque eólico, orientado pelos estudos de Walker et al (2014).

Durante a aplicação dos questionários com a autorização do informante utilizou-se para registro das informações um gravador digital. A transcrição da gravação auxiliou na reprodução exata dos dados coletados. O resultado das transcrições permitiu estabelecer sete temas, sendo o espaço de lazer uma das categorias analisadas. A etapa de transcrição dos dados e posterior extração dos temas foi essencial para a análise e interpretação das informações

A análise dos dados fundamentou-se na Escala Likert permitindo ao entrevistado atribuir ordem de importância aos temas abordados. Rensis Likert (1932) foi responsável pelo desenvolvimento dessa escala onde buscava estabelecer formas de mensuração dos comportamentos no universo das ciências comportamentais. A escala de verificação de Likert fundamenta-se em utilizar-se de um conceito teórico não observável como o amor, medo, raiva, etc. e desenvolver uma somatória de afirmações relacionadas ao tema, em seguida os respondentes emitirão seu grau de concordância (SILVA JÚNIOR; COSTA, 2014). De forma complementar utilizou-se dos estudos de Pasqualetti (2011a; 2011b), para refletir sobre as razões para rejeição ou oposição à energia eólica em termos de processos de paisagem, Sociedade e Território - Natal. Vol. 29, N. 2, p. 49-69, Jul./Dez. de 2017 
aplicando o padrão elaborado por Pasqualetti (2011a) de imobilidade, imutabilidade, solidariedade, imposição e lugar.

\section{RESULTADOS}

A instalação de parques eólicos ao longo da zona costeira do Nordeste brasileiro tem resultado em impactos negativos não só ao meio ambiente (desmatamento, soterramento de lagoas, aterramento e aplainamento dos campos de dunas), mas tem afetado a reprodução sociocultural das populações locais que residem nessas áreas comprometendo suas fontes de renda e de autoconsumo (MEIRELES, 2011; BROWN, 2011; LOUREIRO et al., 2015, MEIRELES, et al., 2015; GORAYEB et al., 2016; GORAYEB; BRANNSTROM, 2016). Os espaços naturais de uso comum ou comunitário estão ameaçados de extinção (DIEGUES; MOREIRA, 2011). A ausência de documentação legal quanto à posse da terra tem favorecido a inserção de investimentos privados, aumentando constantemente a pressão sob os territórios tradicionais (LEROY; MEIRELES, 2013; GORAYEB et al., 2016; BRANNSTROM et al., 2017). As populações locais são expropriadas de seus territórios desestruturando suas práticas espaciais). Resistindo as mudanças, os grupos familiares protagonizam processo de resistência e luta coletiva (MEIRELES, 2011).

A análise dos dados obtidos pelos questionários e alimentado pelos dados qualitativos possibilitou identificar que os recursos naturais representam uma importante fonte de lazer e afetividade para os residentes do Cumbe. As famílias se orgulham das paisagens naturais que compõem o seu território e enfatizam a relação harmônica que construíram ao longo do tempo com o ambiente onde vivem. Esses ambientes ocupam um espaço importante porque as dunas, as lagoas interdunares e o mar são utilizados pelas famílias como espaços de lazer para jogos de bola, montagem de barracas para vendas de alimentos, banhos nas lagoas e no mar e para confraternizações das famílias.

Em 2008, a instalação do parque eólico alterou as formas de uso das dunas, das lagoas interdunares e do mar ocasionando restrição no seu uso comunitário. Essas modificações acarretaram em uma total rejeição ao empreendimento, culminando, num momento inicial, no fechamento da estrada de acesso ao empreendimento em setembro de 2009 por 19 dias. Limitações em seus espaços de lazer contribuíram para que os moradores se opusessem ao empreendimento depois do período de construção, prolongando-se para a fase de manutenção. $\mathrm{Na}$ figura 2 podemos observar a atual situação da comunidade cabos condutores de 
eletricidade, placas de limitação de acesso tem comprometido os espaços de lazer da comunidade.

Figura 2: Limitações de acesso ao mar e aterramento das lagoas interdunares.

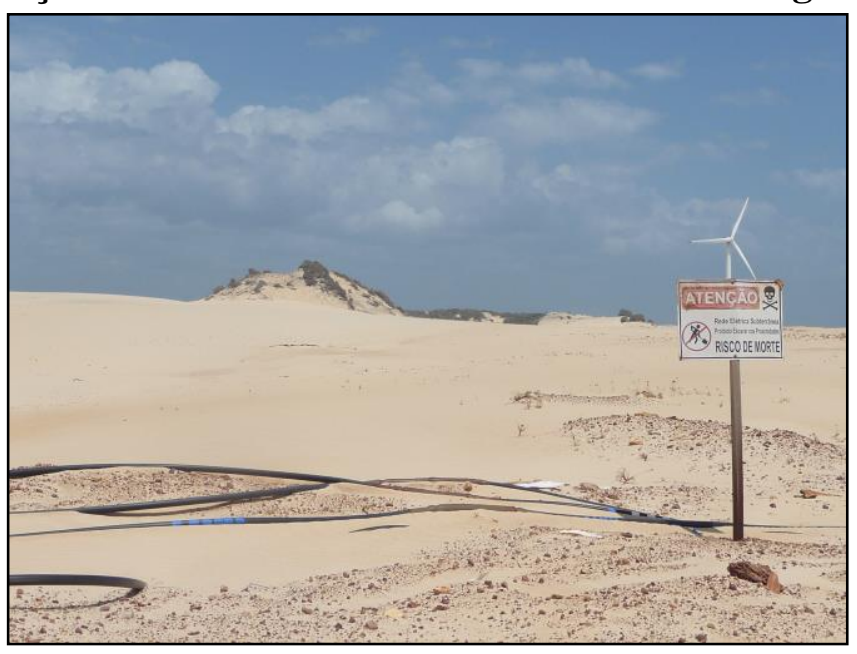

Fonte: Leilane Oliveira Chaves, 2016.

No Cumbe, constatamos a presença de cinco processos descritos por Pasqualetti (2011a). Ressalta-se que a categoria espaço de lazer não foi discutida isoladamente pelo autor, mas ao analisarmos os processos expostos por Pasqualetti (2011a) imposição, solidariedade, imutabilidade e lugar temos elementos suficientes para abordamos as relações afetivas que os residentes locais mantinham com os ambientes impactados após a instalação do projeto eólico. No quadro 1 ao versarmos sobre os possíveis motivos de rejeição ou oposição ao projeto eólico encontram-se descritos os conceitos de Pasqualetti (2011a), a definição e a sua manifestação no Cumbe.

Destacamos várias maneiras e formas em que os entrevistados descrevem os processos. Residentes argumentam que a instalação do parque eólico ocasionou mais prejuízos do que benefícios, como indica o entrevistado 16 "tem muito prejuízo, a gente era livre, agora você não pode ir ali, ir acola, tem canto aí que é perigoso, cheio de fiação, pode acabar morrendo alguém, se estoura um fio desse ninguém sabe" (Entrevistado 16, 33 anos, 12/08/2016). A reclamação da perda do livre acesso por uma área que foi ocupada por várias gerações pode ser entendida como a imposição e violação do conceito lugar. 
Quadro 1: Motivos a rejeição ou oposição ao projeto eólico no Cumbe

\begin{tabular}{|c|c|c|}
\hline $\begin{array}{l}\text { PROCESSO } \\
\text { PAISAGEM }\end{array}$ & DESCRIÇÃO & CASO CUMBE \\
\hline IMOBILIDADE & $\begin{array}{l}\text { A energia eólica não se concilia } \\
\text { com os aspectos naturais, culturais } \\
\text { e sociais existentes }\end{array}$ & $\begin{array}{l}\text { O parque eólico não considerou o modo } \\
\text { de vida local }\end{array}$ \\
\hline IMUTABILIDADE & $\begin{array}{l}\text { As pessoas não se adaptam a } \\
\text { mudanças bruscas na paisagem, } \\
\text { pois a constância da paisagem } \\
\text { concede tranquilidade as pessoas }\end{array}$ & $\begin{array}{l}\text { (1) Paisagem artificial; (2) Alteração dos } \\
\text { meios de vida após a instalação do parque } \\
\text { eólico }\end{array}$ \\
\hline SOLIDARIEDADE & $\begin{array}{l}\text { As relações comunitárias são } \\
\text { interrompidas após a chegada da } \\
\text { energia eólica }\end{array}$ & $\begin{array}{l}\text { (1) Interferência nos espaços de lazer, } \\
\text { atividades domésticas e festivas; (2) } \\
\text { Contribuiu para o fortalecimento da luta } \\
\text { pela identidade quilombola }\end{array}$ \\
\hline IMPOSIÇÃO & $\begin{array}{l}\text { A população não está envolvida no } \\
\text { projeto eólico, muitas vezes não } \\
\text { recebendo nenhum tipo de } \\
\text { rendimento }\end{array}$ & $\begin{array}{l}\text { (1) O parque eólico bloqueou áreas de } \\
\text { uso comum; (2) Uso de linguagem } \\
\text { técnica durante as reuniões dificultando a } \\
\text { compreensão dos residentes; (3) Não há } \\
\text { pagamentos de royalties ou aluguéis para } \\
\text { residentes locais; (4) Existência de outros } \\
\text { tipos de conflitos por recursos antes da } \\
\text { chegada do parque eólico (aquicultura de } \\
\text { camarão) }\end{array}$ \\
\hline $\begin{array}{l}\text { LUGAR } \\
\text { (PLACE) }\end{array}$ & $\begin{array}{l}\text { As relações afetivas com o local } \\
\text { são comprometidas }\end{array}$ & $\begin{array}{l}\text { Abandono de atividades diárias devido ao } \\
\text { medo de choques elétricos e } \\
\text { intimimdação pelos vigias do } \\
\text { empreendimento (presença de cancela no } \\
\text { portão do parque eólico) }\end{array}$ \\
\hline
\end{tabular}

Fonte: Elaborado pelos autores com base em Pasqualetti, 2011a.

A rejeição ao parque eólico pela característica de imposição ganha maior força entre os moradores porque as limitações de acesso ao território, originaram proibições de acesso aos recursos naturais. A pesquisa constatou que das 19 famílias entrevistadas, 14 afirmaram que após a instalação do parque eólico houve alterações no acesso aos recursos naturais, concentrando pontuações no escore 1 (muita alteração) e no escore 2 (alteração). Os campos de dunas local destinado para a instalação do projeto eólico representa um ambiente de relevante importância para a convivência comunitária, como indica o entrevistado 2 :

\footnotetext{
A comunidade ela se movimenta tanto nas dunas no período dos inverno que você não consegue tá na comunidade. Você quer subir nas dunas. É a tarde e não tem hora. É naquele tempo nublado e todo mundo arruma diversão. Então todo mundo procura o que fazer nas dunas. Jogo de bola começa no inverno. O jogo de bola já começa lá nas dunas. É tanto que os domingos fica bem animado lá nas dunas porque os menino já faz torneio lá nas dunas e aí leva as torcidas e nois vamos e tudo (Entrevistado 2, 43 anos, 28/10/2016).
}

Esta perspectiva demostra a importânia das dunas nas atividades de lazer, incluindo o esporte e outras diversões que fazem parte do cotidiano da comunidade. Residentes 
argumentam que o projeto eólico foi instalado sem levar em consideração a relação que a comunidade mantinha com os seus recursos naturais. Duas famílias destacam que o empreendimento não compreende o modo de vida da comunidade e por isso sempre se manteve distante dos residentes. Como destaca o entrevistado 6: "eu sempre vivi aqui, gosto muito do Cumbe, mas o que eu vejo é que o povo apodrece aqui, um projeto desse aí ele não conhece ninguém, não dá valor ao nosso modo de convivência, entendeu. Essa nossa região aqui. Esse nosso interior não existe em canto nenhum" (Entrevistado 6, 34 anos, 12/08/2016). Segundo este morador, o parque eólico teve um efeito quase tóxico na comunidade; também mostra o afeto muito forte pelo território, considerado um espaço único no mundo, e percebendo o parque eólico como uma violação do espaço.

O processo de imposição foi colocado em outras palavras por outros entrevistados, como a entrevistada 10, que destaca que as mudanças comprometeram o uso dos recursos naturais de diferentes formas "eu acho isso [impactos da energia eólica] gravíssimo, a gente não tem mais as coisas que a gente tinha antes. Você já viu até onde eles chegaram?” (Entrevistada 10, 53 anos, 10/09/2016). Alguns residentes temem a expansão do empreendimento já que possuem a outorga para ocuparem os campos de dunas, como indica a entrevista 9 "então tipo assim se ele [parque eólico] já instalou aí já privatizou quase as dunas toda, ainda falta muito espaço aí que eles poderiam construir então é ficar privatizado geral essas dunas aí pra gente" (Entrevistada 9, 37 anos, 30/10/2016).

O entrevistado 2 também expõe a forma como o projeto foi instalado na comunidade desprezando as relações que os moradores mantinham com os recursos naturais. Ele relata que:

É assim, os empreendimentos né as vezes eles vêm muito sutil, pegam a gente as
vezes muito de surpresa e as vezes você sabe só uma conversa, diz que vem, mas é
tão distante daquilo que você vivência que você acha que é só imaginação. Não eu
acho que não. E aí quando você se bate com a realidade ela é muito cruel porque
eles vêm sem dar importância a um povo que mora ali e aí foi numa época que a
gente se sentiu de um mínimo de importância de um povo que vivia ali, que tinha
seus modos de vida, mas muito bruscamente eles vêm com violência de impacto tão
grande psicologicamente que as vezes você não quer aceitar porque chega a doer
tanto. É tanto que pessoas sofreram psicologicamente, ficaram doente mesmo por
conta do transtorno que a eólica naquele período causou (Entrevistado 2,43 anos,
$28 / 10 / 2016$ ).

A solidariedade, outra questão discutida por Pasqualetti (2011a), corresponde a um rompimento das relações comunitárias entre os moradores locais e o seu ambiente natural. A instalação do parque eólico comprometeu de forma diferenciada as atividades de lazer 
desenvolvidas nas dunas, lagoas interdunares e no mar (FIGURA 3). Nas dunas e nas lagoas os espaços de lazer foram totalmente comprometidos após a instalação do parque eólico, haja vista que grande parte das lagoas foram aterradas ou privatizadas. Pela proximidade com o núcleo residencial são ambientes utilizados por um maior número de residentes, como indica uma entrevistada: "as nossas lagoas eram um divertimento né. Tumava muito banho, nadava, levava roupa pra lavar. Quando era no inverno era muita lagoa parecia rio" (Entrevistada 11, 55 anos, 10/09/2016).

As lagoas representam para os moradores um importante espaço de lazer comunitário, como indica uma entrevistada: "nas lagoas de primeiro a gente podia ir tomar um banho, lavar uma roupa, agora dizem que ninguém pode ir mais quando os inverno são bons, porque pode levar choque nesses fio [cabos que levam a energia elétrica do aerogerador até a subestação]. Eles ficam fechando os portões [da cancela] pra ninguém passar" (Entrevistada 10, 53 anos, 10/09/2016). Os momentos de lazer nas lagoas foram recordados por diversos moradores, como relembrou a entrevistada 8:

\begin{abstract}
Não pode nem tumar banho nas lagoas que antigamente quando [um morador] tinha as barracas dele lá no morro [duna] nois ia era pra lá de noite era o luau que tinha nois vinha de madrugada, em qualquer hora, agora ninguém pode. As barracas que era bom de noite não existe mais banho de lagoa porque impatou [proibiu] mesmo (Entrevistada 8, 52 anos, 29/10/2016).
\end{abstract}

As atividades nas lagoas ocorriam durante o dia e até mesmo a noite e envolviam diversos moradores da comunidade, como indica a entrevistada 11:

\begin{abstract}
Se você vise o divertimento que tinha nesses morro [dunas] até aquele homem que tem um problema na vista ele botou foi uma mercearia no morro. Inté festa tinha. Era luau de noite parecia uma cidade. As lagoas tudo cheia, tudo cheia. O pessoal botava uma vendinha lá porque tinha um tal de luau que a gente ia. Butava umas barraquinhas pra vender as coisas. A gente ia tumar um banho quem quisesse ficar mais tarde ficava, quem quisesse vim mais cedo nois vinha aí a gente tinha esse lazer né. Era calmo todo mundo amigo nunca teve barbaridade [violência, confusão] lá em riba [cima] do morro".
\end{abstract}

O mar como espaço de lazer foi destacado por alguns grupos familiares. Nos dados levantados em campo evidenciou-se que em decorrência da distância do núcleo residencial poucas famílias se deslocavam até o mar para momentos de lazer, principalmente pela proximidade com as lagoas interdunares.

Durante a construção do empreendimento o acesso ao mar foi proibido após o parque entrar em fase de operação. $\mathrm{O}$ acesso só foi liberado em decorrência de diversos protestos e 
somente para moradores da comunidade. Entretanto, residentes argumentam que mesmo morando no Cumbe em alguns momentos ainda necessitam apresentar documentação para terem livre acesso ao mar. Segunda a entrevistada 9, "hoje a gente ainda consegue passar restritamente, mas chegou um tempo de você não poder ir pra praia, poxa e toda a vida você usou a praia e agora você não poder passar pra praia, você tá lá, você se limita, hoje você entra, amanhã você não entra, pra mim isso e uma alteração muito grande" (Entrevistada 9, 37 anos, 30/10/2016).

Apesar do núcleo residencial estar distante cerca de $10 \mathrm{~km}$ do mar os moradores mantinham o hábito de ir à praia com frequência. Segunda a entrevistada 7 "de primeiro a gente podia ir a hora que quisesse pra praia vir e não tinha nenhum problema. Agora se você tem um carro e que tenha a placa de Fortaleza você já é barrado, não passa, tem que ser de Aracati ou se não a pessoa ir de carroça se não for eles barram, eles não deixam passar" (Entrevistada 7, 19 anos, 10/09/2016). Em outra fala a entrevistada 8 informa que "pra praia só se for de carro e se for de capacete, se for sem capacete volta pra trás, é porque antigamente a gente passava ia de pé, ia quase todo mundo de pés e nois ia e voltava e não tinha isso né" (Entrevistada 8, 52 anos, 29/10/2016).

Alterações nas formas de convivência da comunidade com os recursos naturais tem influenciado no abandono dos espaços de uso comum, resultando em um território do medo pela presença de cabos condutores de eletricidade, seguranças, cercas e portões. Como indica o entrevistado 4:

\footnotetext{
Onde tá montado uma torre eólica existe ramais elétricos de grande potência então a gente tem medo de uma descarga elétrica uma coisa prejudicar um banho que você tá tomando numa lagoa próxima. Se isso acontecer minha amiga é como um chefe me disse aí tem enterro não, o cara simplesmente desaparece lá, é uma potência muito grande, então esse espaço de dunas, esse espaço de dunas pra nois tá limitado, super limitado (Entrevistado 4, 52 anos, 12/08/2016).
}

Moradores locais alegam que não desfrutam mais dos espaços de lazer na comunidade por temerem possíveis acidentes já que as fiações ficam expostas sobre os campos de dunas. Segundo o entrevistado 6 "os $\underline{\text { morros }}$ [dunas] tão cheios de fie [fio] elétrico aí, se um carro esbarrar um fio desse. Ainda pouco istorou um carro aí, se pega uma pessoa no morro. De primeiro não tinha isso não, não existia isso não" (Entrevistado 6, 34 anos, 12/08/2016). Os cabos condutores de eletricidade estão fixados em lugares de mobilidade dos moradores locais. A preocupação maior dos residentes é que as fiações estão nos percursos utilizados para se deslocarem até as lagoas interdunares e o mar.

Sociedade e Território - Natal. Vol. 29, N. 2, p. 49-69, Jul./Dez. de 2017 
Muitos moradores ainda hoje buscam manter os mesmos hábitos mesmo após a instalação do parque eólico, porém a entrevistada 9 relata que por diversas vezes quando estava com sua família nas lagoas era solicitado pelos seguranças do empreendimento que se retirassem do local. Ela relata que:

\begin{abstract}
Olha a gente deixou de frequentar lagoas que a gente ia. Três lagoas aqui que eram muito, a do murici eu posso dizer que era a melhor lagoa da gente ir. Essa lagoa a gente teve uma coisa muito forte por causa das eólicas, de você tá lá na lagoa, na época da lagoa e chegar polícia para lhe tirar de dentro da lagoa então pra mim isso é uma alteração muito grande (Entrevistada 9, 37 anos, 30/10/2016).
\end{abstract}

Em decorrência da ausência de chuvas e das constantes proibições de acesso aos campos de dunas, os moradores afirmaram que a cerca de 5 anos não estavam mais usufruindo das lagoas interdunares, entretanto, no início do ano de 2017 o estado do Ceará apresentou um volume significativo de chuvas, contribuindo para que os moradores da comunidade voltassem a desfrutar desse recurso natural como espaço de lazer, como se observa na figura 3.

Figura 3 - Momentos de lazer nas dunas e lagoas interdunares.

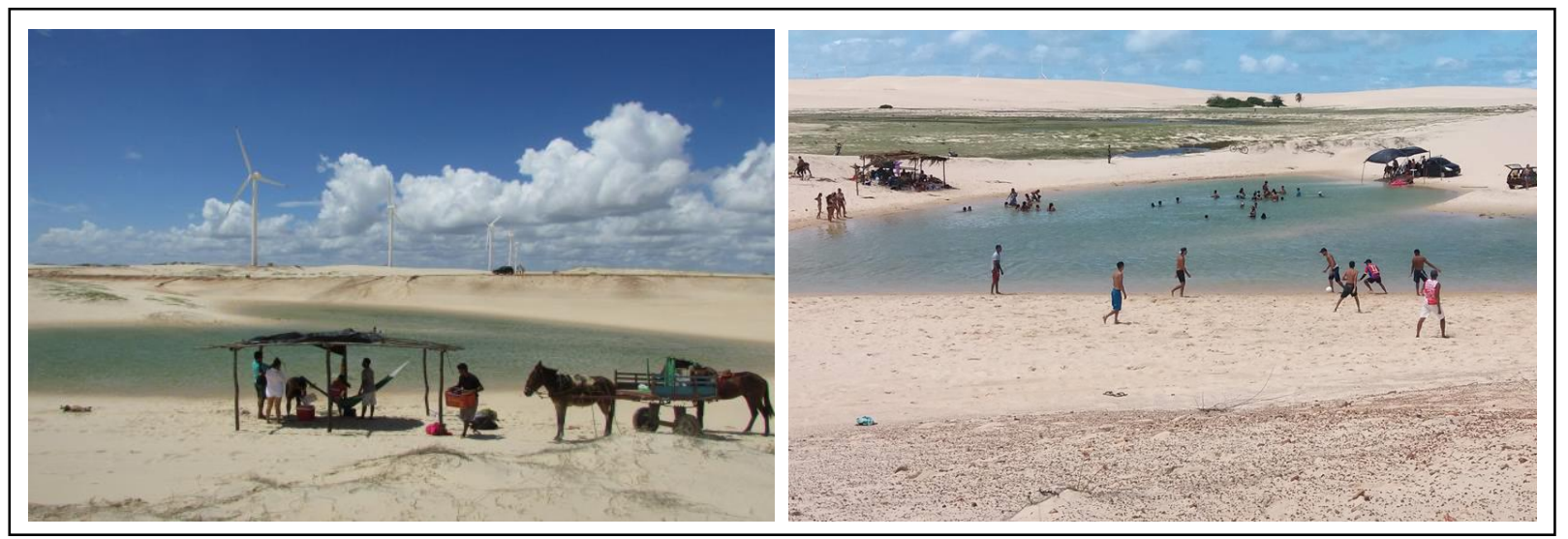

Fonte: Victor Souza, 2017.

A manutenção do acesso aos espaços de lazer foi uma categoria mencionada por diversos residentes. Quando se discute a relevância do lazer na vida do indivíduo a entrevistada 9 indica a sua importância na vida dos residentes locais: 
A gente não precisa só do trabalho. A gente precisa do lazer também e a nossa duna, a nossa duna daqui tem uma importância muito grande pra gente de lazer, tem a pesca também que é muito importante. Aí você pergunta: Você escolhe duna ou praia? Aí o pessoal diz: Se eu fosse você eu escolhia o rio, porque ele é mais importante pra você por causa da alimentação, pra garantia de renda pra vocês, mas como é que a gente vevi só de trabalho então é assim, é um coisa muito séria porque você precisa trabalhar e a limitação é muito grande na área do rio e das dunas também, tanto por essa parte de diversão de dunas, de lagoas (Entrevistada 9, 37 anos, 30/10/2016).

O retorno aos espaços de lazer em especial nas lagoas interdunares demostram a relevância desse ambiente para a manutenção do bem-estar do indivíduo e para o seu convívio social.

Outra questão discutida por Pasqualetti (2011a), o lugar, também se relaciona aos espaços de lazer. No relato apresentado pelo entrevistado 6, "o verde é o que traz riqueza para qualquer lugar, o verde o natural da comunidade" (Entrevistado 6, 34 anos, 12/08/2016). O entrevistado relembra em seu relato a paisagem que a comunidade tinha antes da instalação do parque eólico. As transformações que refletem a situação da comunidade em 2017 desmatamento da vegetação das dunas, aterramento e privatização das lagoas interdunares e a presença de cercas, placas e cancelas não representam a percepção que os moradores guardavam na memória sobre a comunidade.

Mesmo existindo moradores que ainda em 2017 buscam momentos de lazer nas dunas, nas lagoas interdunares e no mar e que lutam e reivindicam por esse direito, outros moradores, principalmente os mais antigos, argumentam que a paisagem no Cumbe não é mais a mesma após a instalação do parque eólico, em especial os campos de dunas. Para essas pessoas as características da paisagem se transformaram. Olhar para elas e ver os aerogeradores não traz mais felicidade.

As conexões emocionais e materiais com o local foram comprometidas pelo parque eólico. Alguns moradores, principalmente os mais antigos, consideram que a paisagem não é mais natural. Como afirma uma entrevistada "eu gosto da natureza natural, eu penso meus Deus do céu como o homem é capaz de fazer isso aqui, eu não olho com admiração, olha que lindo o catavento [aerogerador] não sei o que, eu fico com aquela ideia, meu Deus como é que o homem tem coragem de fazer isso com uma duna" (Entrevistada 9, 37 anos, 30/10/2016). De acordo com o entrevistado 2 (Entrevistado 2, 43 anos, 28/10/2016), a paisagem que hoje visualiza no Cumbe não representa mais as imagens que tem em sua memória. O entrevistado afirma que não consegue mais reconhecer a paisagem que fazia parte da sua vida diária: 
Quando essa eólica chegou é como se o paisagismo [paisagem] tivesse assim mudado drasticamente, era como se tivesse num lugar e não reconhecesse, então aquilo que você tinha na memória é como se você não reconhecesse aquilo que tava guardado na sua memória, tá entendendo. Você via coisas bem agressivas, aquele olhar que você tinha antes, então dava pra perceber essa agressividade até no olhar pra paisagem (Entrevistado 2, 43 anos, 28/10/2016).

Este pensamento parece com o que Pasqualetti (2011a, p. 914) indica, quando ele se refere a dois assuntos chaves na oposição à energia renovável: que a paisagem ou local gera sentimentos emocionais quanto a sua estabilidade ou permanência no tempo, gerando confronto emocional.

Residentes relatam que não possuem mais satisfação em caminhar pelos campos de dunas em função das limitações impostas diariamente pelo parque eólico. Como indica a entrevista 9, "você só pode ir por aqui, agora você só pode ir por acolá, aí dificulta você ir, aí você fica perdendo o gosto de você subir as dunas porque fica interrompido, porque chamam polícia pra você e tudo" (Entrevistada 9, 37 anos, 30/10/2016). Como podemos observar no relata da entrevistada 9 o parque eólico tem interferido nos vínculos emocionais que os moradores mantinham com o seu território. Algumas atividades de lazer não estão mais sendo praticadas pela necessidade de confronto com os gestores do empreendimento. Algumas famílias têm optado pelo abandono de antigas práticas.

\section{DISCUSSÃO}

Ao abordarmos as discussões de Pasqualetti (2011a; 2011b) para a comunidade do Cumbe, identificamos que todas as questões expostas pelo autor contemplam a realidade vivenciada na comunidade quando se discute as interferências do parque eólico nos espaços de lazer da comunidade. As questões imposição, imobilidade, imutabilidade, solidariedade e lugar, quando relacionadas aos impactos aos espaços de lazer nos permitem evidenciar novos elementos de rejeição ao projeto eólico no Cumbe em comparação a outros estudos. Proibições e limitações de acesso a setores do território utilizados para o convívio comunitário fortalecem protestos contra o projeto eólico.

As questões identificadas por Pasqualetti (2011a; 2011b) tem uma materialização observada no caso do Cumbe. Quando problematizamos o que passa nas dunas, nas lagoas interdunares e no mar como espaço e objeto de afeto dos residentes, apreciamos com detalhe as questões imobilidade, imutabilidade, solidariedade, imposição e lugar (place). Na nossa análise, os membros da comunidade Cumbe entendem que as dunas são áreas de lazer para a 
comunidade, porém sem título da terra. Ao observar seu território ser convertido em área industrial, com perigos, arrendada por meios opacos pela empresa eólica, para a geração de energia e lucro, os membros da comunidade interpretam a transformação de um espaço de lazer como uma imposição e uma violação do lugar, alimentando o conflito permanente entre residentes da comunidade e o parque eólico.

Estudos de Meireles (2011), Brown (2011), Ribeiro (2013), Loureiro et al. (2015), Meireles, et al. (2015), Gorayeb, et al. (2016) e Gorayeb e Brannstrom (2016), evidenciam a existência de mudanças profundas no modo de vida das populações costeiras no Ceará. Os resultados dessas pesquisas mostraram que os projetos eólicos têm ameaçado os vínculos materiais e simbólicos mantidos ao longo de várias gerações. Divergências de uso e apropriação do território relacionam-se a visões diferenciadas de um mesmo território, de um lado vista como expressão da identidade de um grupo - em defesa da manutenção de suas relações sociais, e de outro, vista como mercadoria - ligadas ao setor empresarial e agentes do Estado que visam a obtenção de lucros. Esses conflitos eclodem em decorrência de tensões no processo de reprodução dos modelos de desenvolvimento, envolvendo grupos sociais com diferentes modos de apropriação, uso e significação do território. Tendo origem quando suas formas de apropriação do meio são interrompidas por atividades empreendidas por outros grupos (ACSERALD, 2004).

$\mathrm{Na}$ atualidade, os principais conflitos ainda se referem ao uso pleno do território e aos impactos que o parque eólico ocasionou aos meios de vida, já que essas atividades ainda integram a maior parte da renda e do consumo alimentar da comunidade. Aprofundar o conhecimento sobre essas atividades ajuda a fazer "visível" os povos "invisíveis" (LEROY; MEIRELES, 2013). A insegurança fundiária e a "invisibilidade" das atividades de subsistência criam um cenário ainda não contemplado por Pasqualetti (2011), na sua síntese dos conflitos entre comunidades e projetos de energia renovável.

O estudo de Brown (2011) mostrou desequilíbrios nos impactos da energia eólica, ficando os seus benefícios distribuídos regionalmente e os impactos negativos a nível comunitário. No Cumbe, o autor identificou que a comunidade está imersa em inúmeros impactos negativos, existindo poucos benefícios diretos, e alguns deles obtidos após muitos protestos, como o fechamento da estrada que dá acesso ao parque eólico em 2009. Esses benefícios dizem respeito a compensações por danos causados pelo próprio parque, geração de empregos temporários e a ampliação dos pequenos comércios locais, mas o presente estudo indica que a quebra de laços afetivos com o lugar, a maneira de implantação, e a existência de Sociedade e Território - Natal. Vol. 29, N. 2, p. 49-69, Jul./Dez. de 2017 
diferentes conflitos no território antes mesmo da instalação do empreendimento eólico dificilmente serão apaziguados por qualquer tipo de compensação. $\mathrm{O}$ fato do conflito entre a comunidade e o parque eólico se prolongar depois do fechamento da estrada sugere as raízes profundas do conflito. Nos estudos de Brown (2011) evidenciou-se muito otimismo sobre as compensações e mitigações, talvez porque o autor não compreendeu as dimensões afetivas que as populações locais mantêm com as terras que ocupam.

\section{CONCLUSÕES}

No Ceará, os parques eólicos foram construídos em áreas costeiras, muitas vezes em dunas, manguezais e planícies onde diretamente e indiretamente estão em conflito com os usuários de recursos. A insegurança fundiária facilitou a instalação do parque eólico nas dunas que os residentes da comunidade Cumbe ocupam há várias gerações, porém, o poder público não reconhece os moradores locais como donos das terras tradicionalmente ocupadas. Além disso, a falta de políticas consistentes garantindo direitos às terras contribuem para o estado de permanência dessa insegurança. A questão da insegurança fundiária é citada com um fator que gera conflitos sobre a energia eólica (BRANNSTROM et al., 2017). O caso Cumbe afirma esta interpretação, assim requeresse cautela em interpretar as afirmações otimistas de Juarez et al. (2014) e Silva et al. (2005) sobre os impactos sociais da energia eólica. A análise do conflito pelas questões imutabilidade, solidariedade, imposição e lugar mostram as relações afetivas entre a comunidade e as dunas, lagoas interdunares e o mar, explicando por que o conflito se prolongou bem depois do fechamento da estrada, em 2009, e extendendo-se durante o período de manutenção. Reconhecemos que as dunas e o mar também representarem fontes de renda e de autoconsumo para a comunidade Cumbe e outras comunidades costeiras. O uso produtivo desses espaços, e os vínculos entre a identidade quilombola e o conflito com o parque eólico, serão discutidos em análises futuros.

\section{REFERÊNCIAS}

ACSELRAD, Henri. Conflitos ambientais no Brasil. Rio de Janeiro:Relume-Dumará, 2004. AQUILA, Giancarlo; PAMPLONA, Edson de Oliveira; QUEIROZ, Anderson Rodrigo de; ROTELA JUNIOR, Paulo; FONSECA, Marcelo Nunes. An overview of incentive policies for the expansion of renewable energy generation in electricity power systems and the Brazilian experience. Renewable and Sustainable Energy Reviews, n. 70, p. 1090-1098, abr. 2017. 
BEBBINGTON, Anthony. Capitals and Capabilities: A Framework for Analyzing Peasant Viability, Rural Livelihoods and Poverty. World Development, v. 27, n. 12, p. 2021-2044, dez. 1999.

BELL, Derek; GRAY, Tim; HAGGETT, Claire; SWAFFIELD, Joanne. Re-visiting the 'social gap': public opinion and relations of power in the local politics of wind energy.

Environmental Politics, v. 22, n. 1, p. 115-135, fev. 2013.

BRANNSTROM, Christian; GORAYEB, Adryane; MENDES, Jocicléa de Sousa; LOUREIRO, Caroline Vitor; MEIRELES, Antonio. Jeovah de Andrade; SILVA, Edson Vicente da; FREITAS, Ana Larissa Ribeiro de; OLIVEIRA, Rafael Fialho de. Is Brazilian wind power development sustainable? Insights from a review of conflicts in Ceará state. Renewable and Sustainable Energy Reviews, v. 67, p. 62-71, jan. 2017.

BRASIL. Mapa do Potencial eólico brasileiro. Brasília: Ministério de Minas e Energia, 2001.

BROWN, Keith Brower. Wind power in northeastern Brazil: Local burdens, regional benefits and growing opposition. Climate and Development, v. 3, n. 4, p. 344-360, out. 2011.

DENCKER, Ada de Freitas Manete. Métodos e técnicas de pesquisa em turismo. São Paulo:Futura, 1998.

DIEGUES, Antonio Carlos Sant'Ana; MOREIRA, Andre de Castro. Espaços e recursos naturais de uso comum. São Paulo: NUPAUB, 2011.

FILGUEIRAS, Alexandre; SILVA, Thelma Maria V. Wind energy in Brazil—present and future. Renewable and Sustainable Energy Reviews, v. 7, n. 5, p. 439-451, out. 2003.

GORAYEB, Adryane; BRANNSTROM, Christian. Caminhos para uma Gestão Participativa dos Recursos Energéticos de Matriz Renovável (Parques Eólicos) no Nordeste do Brasil. Mercator, v. 15, n. 01, p. 101-115, jan./mar. 2016.

GORAYEB, Adryane; MENDES, Jocicléa de Sousa; MEIRELES, Antonio Jeovah de Andrade; BRANNSTROM, Christian; SILVA, Edson Vicente da; FREITAS, Ana Larissa Ribeiro de. Wind-energy Development Causes Social Impacts in Coastal Ceará state, Brazil: The Case of the Xavier Community. Journal of Coastal Research, v. 75, p. 383-383, mar. 2016.

HUBER, Matthew T; MCCARTHY, JAMES. Beyond the subterranean energy regime? Fuel, land use and the production of space. Transactions of the Institute of British Geographers, 42, 655-668, maio. 2017.

INTERNATIONAL ENERGY AGENCY. Renewable Energy Medium-Term Market Report: Market Analysis and Forecasts to 2021. Paris, 2016. 278p. Disponível em < https://www.iea.org/Textbase/npsum/MTrenew2015sum.pdf $>$. Acesso em 20 dez. 2017.

JACOBSON, Mark Zachary; DELUCCHI, Mark. A. 2011. Providing all global energy with wind, water, and solar power, Part I: Technologies, energy resources, quantities and areas of infrastructure, and materials. Energy policy, v. 39, n. 3, p. 1154-1169. 2011. 
JUÁREZ, Alberto Aquino; ARAÚJO, Alex Maurício; ROHATGI, Janardan Singh; OLIVEIRA FILHO, Oyama Douglas Queiroz de. Development of the wind power in Brazil: Political, social and technical issues. Renewable and sustainable energy reviews, v. 39, p. 828-834. 2014.

LIMA, Maria do Céu. Pesca artesanal, carcinicultura e geração de energia eólica na zona costeira do Ceará. Terra Livre, ano 24, v. 2, n. 31, p. 203-213, jul./dez. 2008.

LEROY, Jean Pierre; MEIRELES, Antonio Jeovah de Andrade. Povos indígenas e comunidades tradicionais: os visados territórios dos invisíveis. In: PORTO, Marcelo Firpo; PACHECO, Tania; LEROY, Jean Pierre (Orgs). Injustiça ambiental e saúde no Brasil: o mapa de conflitos. Rio de Janeiro: FIOCRUZ, p.115-122. 2013

LOUREIRO, Caroline Vitor; GORAYEB, Adryane; BRANNSTROM, Christian. Implantação de energia eólica e estimativa das perdas ambientais em um setor do litoral oeste do Ceará, Brasil. Geosaberes, v. 6, n. 1, p. 24-38, out. 2015.

MARTINS, Fernando Ramos; GUARNIERI, Ricardo André; PEREIRA, Enio Bueno. O aproveitamento da energia eólica. Revista Brasileira de Ensino de Física, v. 30, n. 1, p. 1304-1313, out. 2008.

MEIRELES, Antonio Jeovah de Andrade. Danos socioambientais originados pelas usinas eólicas nos campos de dunas do nordeste brasileiro e critérios para definição de alternativas locacionais. Confins, v. 11, p. 1-20. 2011.

MEIRELES, Antonio. Jeovah de Andrade; GORAYEB, Adryane; LIMA, Gledson Santos de; SILVA, Débora Raquel Freitas da Impactos socioambientais da energia eólica no litoral cearense. In: CORREIA, L. J. A.; OLIVEIRA, Vládia Pinto Vidal de; MAIA, Judária Augusta. Evolução das paisagens e ordenamento territorial de ambientes interioranos e litorâneos. Fortaleza: Expressão Gráfica, 2015.

PACALA, Sthephen; SOCOLOW, Robert. Stabilization wedges: solving the climate problem for the next 50 years with current technologies. Science, v. 305, n. 5686, p. 968-972, ago. 2004.

PASQUALETTI, Martin J. Opposing wind energy landscapes: a search for common cause. Annals of the Association of American Geographers, v. 101, n. 4, p. 907-917, jul. 2011a.

PASQUALETTI, Martin J. Social barriers to renewable energy landscapes. Geographical Review, v. 101, n. 2, p. 201-223, abr. 2011b.

PINTO, Marcia Freire; NASCIMENTO, João Joventino Luís; BRINGEL, Paulo Cunha Ferreira; MEIRELES, Antonio Jeovah de Andrade. Quando os conflitos socioambientais caracterizam um território? Gaia Scientia, Special Issue, p. 271-288. 2014.

PROENÇA, Wander de Lara. O método da Observação Participante: contribuições e aplicabilidades para pesquisa no campo religioso brasileiro. Revista Aulas, n. 4, p. 1-23, abr./jul. 2007.

RIBEIRO, Gilmar Lopes. Parques eólicos - Impactos socioambientais provocados na região da praia do Cumbe, no município de Aracati Ceará. 2013. Tese. (Doutorado em

Sociedade e Território - Natal. Vol. 29, N. 2, p. 49-69, Jul./Dez. de 2017 
Geografia) - Instituto de Geociências e Ciências Exatas, Universidade Estadual Paulista, Rio Claro - SP.

SANTOS, Anna N; BRANNSTROM, Christian. Livelihood strategies in a marine extractive reserve: Implications for conservation interventions. Marine Policy, v. 59, p. 44-52, set. 2015.

SCHEIDEL, Arnim; SORMAN, Alevgul H. Energy transitions and the global land rush: Ultimate drivers and persistent consequences. Global Environmental Change, 22, 588-595. 2012.

SILVA JÚNIOR, Severino Domingos da; COSTA, Francisco José. Mensuração e Escalas de Verificação: uma Análise Comparativa das Escalas de Likert e Phrase Completion. PMKT.

Revista Brasileira de Pesquisas de Marketing, Opinião e Mídia, v. 15, p. 1-16, out. 2014.

SERVA, Maurício; JAIME JUNIOR, Pedro. Observação participante e pesquisa em administração uma postura antropológica. Revista de Administração de Empresas, v. 35, n.1, p. 64-79, mai./jun. 1995.

SILVA, Rodrigo Corrêa da; MARCHI NETO, Ismael de; SEIFERT, Sthephan Silva. Electricity supply security and the future role of renewable energy sources in Brazil. Renewable and Sustainable Energy Reviews, v. 59, p. 328-341. 2016.

SILVA, Neilton Fidelis da; ROSA, Luiz Pinguelli; ARAÚJO, Maria Regina. The utilization of wind energy in the Brazilian electric sector's expansion. Renewable and Sustainable Energy Reviews, v. 9, n. 3, p. 289-309, jun. 2005.

WALKER, Chad; BAXTER, Jamie; OUELLETTE, Danielle. Beyond rhetoric to understanding determinants of wind turbine support and conflict in two Ontario, Canada communities. Environment and Planning A, v. 46, n. 3, p. 730-745, jan. 2014.

Recebido em Setembro de 2017

Aprovado em Dezembro de 2017

Publicado em Dezembro de 2017 